\title{
Intramedullary Blastomycosis in a Child: Case Report
}

\author{
A.M. Parr and D. Fewer
}

\begin{abstract}
Objective: To report a case of spinal intramedullary blastomycosis causing myelopathy. This is the first published case of a pediatric patient with intramedullary blastomycosis and compromised function. Clinical presentation: An otherwise healthy 13-year-old patient was diagnosed with respiratory North American blastomycosis. She subsequently received a five-month course of itraconazole with presumed resolution of the infection. The patient presented again at 14 years of age with a lumbar myelopathy. Magnetic resonance imaging revealed an intramedullary lesion of $1 \mathrm{~cm}$ diameter at the level of T12-L1. Intervention: A T12-L1 laminectomy was performed with a gross total resection of the lesion. Pathological examination and microbiological culture of the specimen was consistent with blastomycosis. Postoperatively, the patient was placed on a five week course of amphotericin B. The patient showed substantial improvement in neurological function. Conclusion: Blastomycosis can present as an isolated intramedullary lesion causing compromised function. It should be considered in the differential diagnosis of a patient with a myelopathy and previously recognized blastomycosis. The prognosis is good with surgical resection.
\end{abstract}

RÉSUMÉ: Blastomycose intramédullaire chez un enfant. Objectif: Rapporter un cas de blastomycose spinale intramédullaire causant une myélopathie. Il s'agit du premier cas publié d'un patient pédiatrique porteur d'une blastomycose intramédullaire ayant des répercussions fonctionnelles. Observation: Une blastomycose respiratoire nord-américaine a été diagnostiquée chez une patiente âgée de 13 ans en bonne santé par ailleurs. Elle a reçu de l'itraconazole pendant cinq mois et on a présumé que l'infection avait été enrayée. La patiente a consulté de nouveau alors qu'elle avait 14 ans pour une myélopathie lombaire. L'imagerie par résonance magnétique a révélé la présence d'une lésion intramédullaire de $1 \mathrm{~cm}$ de diamètre au niveau D12-L1. Intervention: On a procédé à une laminectomie D12-L1 et la lésion a été réséquée. L'examen anatomopathologique et la culture du spécimen ont montré qu'il s'agissait d'une blastomycose. Après la chirurgie, la patiente a reçu de l'amphotéricine B pendant cinq semaines. La fonction neurologique s'est améliorée considérablement. Conclusion: Le tableau clinique de la blastomycose peut être celui d'une lésion intramédullaire isolée ayant des répercussions fonctionnelles. Cette pathologie doit faire partie du diagnostic différentiel chez un patient présentant une myélopathie et qui a des antécédents de blastomycose. Le pronostic est excellent après exérèse chirurgicale de la lésion.

Can. J. Neurol. Sci. 2004; 31: 282-285

Blastomyces dermatitides is a dimorphic fungus endemic to southern, mid-western, and eastern parts of the United States, but has also been seen in Canada. ${ }^{1}$ It is an uncommon fungal infection in childhood. The disease has a range of presentations, with differing severities from asymptomatic to life threatening. The most common presentation is pulmonary, which is not surprising since it is usually acquired through inhalation of airborne spores. After conversion to the yeast form in the lung, various other organ systems may also become involved including skin and bones (the most common), followed by genitourinary tract, central nervous system, and oropharynx. ${ }^{2,3}$ Spread to extrapulmonary sites is likely through a hematogenous route. The spine is the most common site of skeletal involvement and previous reports have focused on vertebral involvement with or without paravertebral abscess and neurological deficit. ${ }^{3-5}$ Although previously reported in an adult with blastomycotic meningitis, this is the first reported case of a pediatric patient with isolated intramedullary blastomycosis causing myelopathy.

\section{CASE RePort}

This 14-year-old female Caucasian, who presented with a two week history of fluctuating right hip and leg pain, paraesthesia, and progressive loss of right foot dorsiflexion, was admitted to our hospital in January 2001. She had been diagnosed with North American blastomycosis on the basis of sputum culture 14 months previously and

From the Division of Neurosurgery, University of Manitoba, Winnipeg, MB Canada.

Received July 4, 2003. Accepted infinalform December 3, 2003. Reprint requests to: Ann M. Parr, 713-39 Parliament St. Toronto, ON M5A4R2 Canada. 


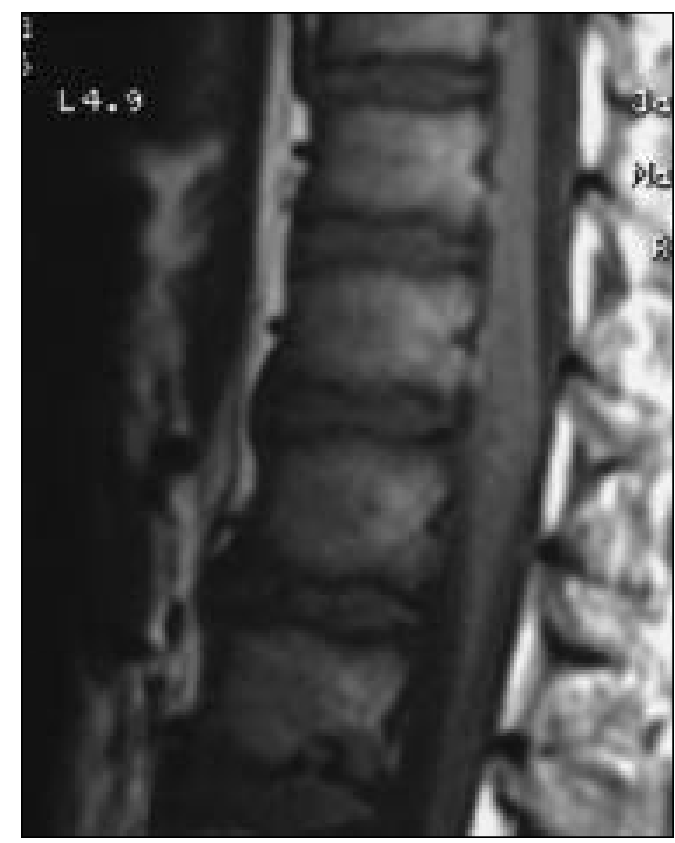

Figure 1: T1-weighted, sagittal MRI scan of the lumbar spine.

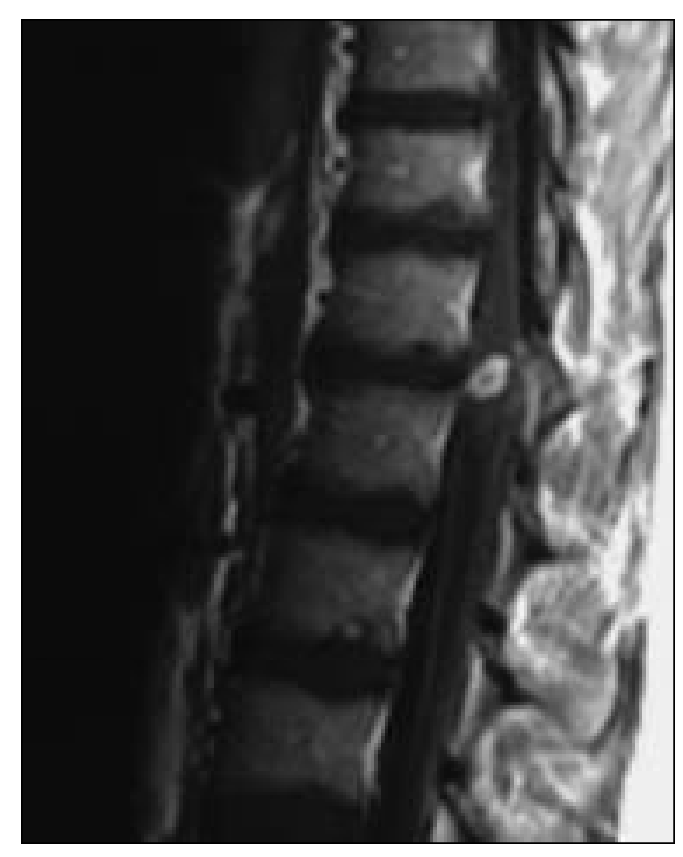

Figure 3: T1-weighted, sagittal MRI scan with gadolinium.

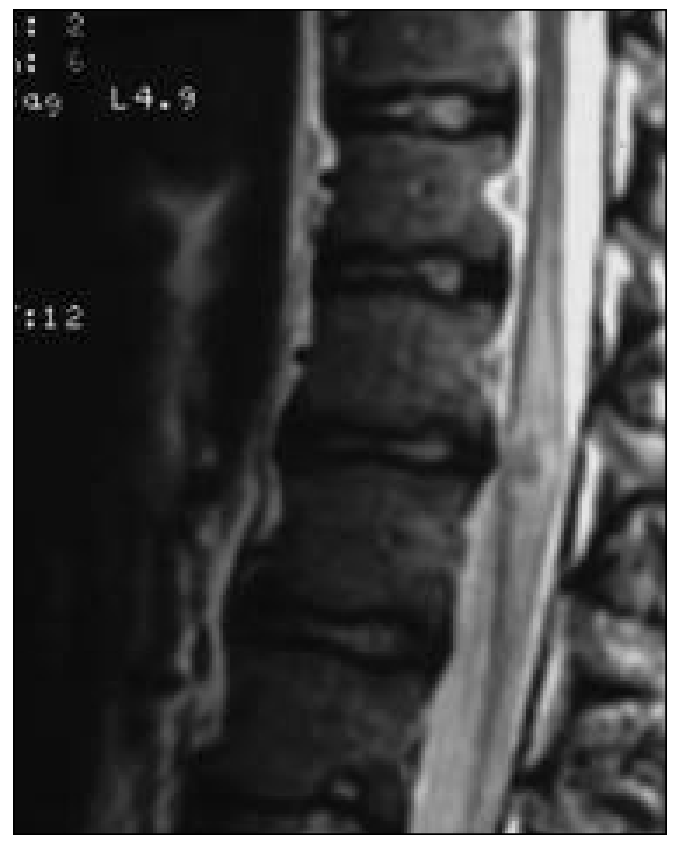

Figure 2: T2-weighted, sagittal MRI scan of the lumbar spine.

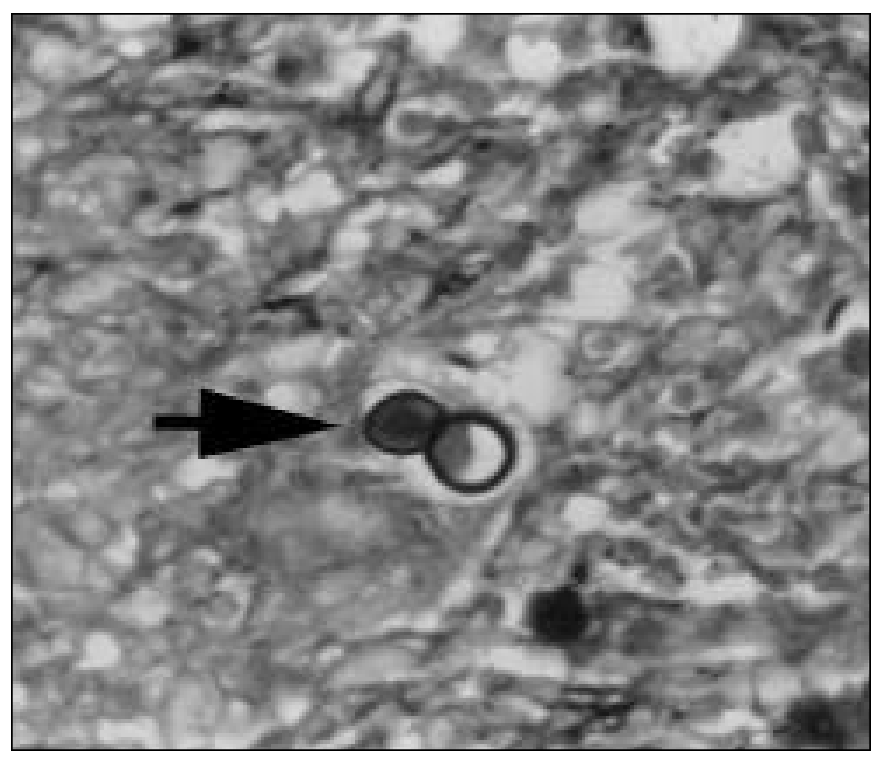

Figure 4: Grocott's methenamine silver stained section of spinal cord demonstrating large, broad-based, unipolar budding yeast-like cells (arrow). Magnification 40X. 
treated with a five month course of itraconazole at a dose of $200 \mathrm{mg}$ once daily. Pulmonary involvement manifested as a unilateral pneumonia not responding to conventional antibiotics, which resolved clinically and radiologically after treatment for blastomycosis. She was otherwise healthy. The source of the blastomycosis was not identified, however it is noted that this organism is endemic to northwestern Ontario where the patient resides.

The physical examination demonstrated weakness in right knee extension and right ankle dorsiflexion and plantar flexion. There was also hypesthesia in the right ankle and foot. Hyperreflexia was noted in the deep tendon reflexes of the right knee and ankle. The results of all laboratory tests were normal, including ESR. Lumbar plain X-rays were unrevealing and a bone scan was negative. Clear cerebrospinal fluid was obtained by lumbar puncture. Gram stain and India ink were negative, and no fungi were noted. Protein was 0.37 , and glucose was 3.1 (serum glucose, 5.4). Nucleated cell count was $3 \times 10^{6}$, with $87 \%$ lymphocytes and $13 \%$ monocytes. Fluid was cultured for bacteria and fungus with no growth after four weeks. Cytology studies were negative. T1-weighted, sagittal MRI scans of the lumbar spine revealed a well-circumscribed round mass of $1 \mathrm{~cm}$ diameter of increased intensity, located within the cord at the T12-L1 level (Figure 1). The spinal cord was moderately enlarged. T2-weighted scans revealed a homogeneous mass of high signal intensity (Figure 2). T1-weighted MRI scans obtained after intravenous gadolinium administration revealed enhancement (Figure $3)$.

The patient underwent surgery on January 19, 2001. A T12-L1 laminectomy was performed. Midline myelotomy was performed. A yellowish, firm, round mass ( $1 \mathrm{~cm}$ diameter), was located using ultrasound. The mass lesion was resected with intact margins. There was no adhesion to the spinal cord or other structures. The dura was closed in a watertight fashion.

Specimens sent for neuropathology demonstrated abscesses in spinal cord tissue characterized by multiple foci of necrosis surrounded by reactive tissue and mixed inflammatory cell infiltrate. Figure 4 shows Blastomyces dermatitides of the spinal cord as demonstrated by Grocott's methenamine silver stain. The organism was also grown in culture.

The patient was prescribed a seven week course of intravenous amphotericin B. This was changed to the lipoidal formulation after two weeks secondary to increasing blood urea nitrogen and creatinine raising concerns about renal damage. The pain, weakness, and paraesthesia in the right leg showed gradual improvement. During the postoperative follow-up period (three months), no recurrence was observed in MRI scans. At six months and one year postoperatively, mild weakness in right ankle dorsiflexion persisted but continued to improve. Hypesthesia had resolved.

\section{DISCUSSION}

Blastomycosis is an infection caused by the inhalation of the fungus. Other organs may become involved, and bone involvement has been noted in 33 to $50 \%$ of cases. ${ }^{6,7}$ Several case reports appear in the literature describing spinal involvement with blastomycosis. ${ }^{3-5,8,9}$ The most common area is the lumbar and thoracic vertebrae, and likely spread is through either the arterial blood supply or Batson's plexus. However, intramedullary spinal cord involvement has rarely been reported without associated extradural bony involvement. A case report from 1953 described a patient with transverse myelopathy exhibiting an intramedullary granuloma at T12 at autopsy, which had no extramedullary association reported. However, this patient also had multiple small cerebral abscesses and blastomycotic meningitis. ${ }^{10}$ Generally, blastomycosis of the spine presents with indiscriminate involvement of the vertebral bodies with all the bony elements of the spine being affected, and variable involvement of the disc space., ${ }^{4,5}$ Intraspinal manifestations of blastomycosis include epidural granuloma or abscess causing transverse myelopathy or spinal cord compression. These have been reported in both adults and children. ${ }^{4,8}$

This child demonstrated findings of spinal cord dysfunction on initial presentation, however, bony lesions were absent. She also did not demonstrate symptoms of other CNS involvement, such as blastomycotic meningitis, also a well-recognized entity. ${ }^{11}$ The clinical findings of spinal cord compression resolved with surgical removal of the lesion and no recurrence was seen on follow-up MRI. Surgery may play an important role in spinal blastomycosis, either diagnostic or therapeutic. Surgery as therapy is useful in those cases in which there is instability and/or spinal cord compression. In the present case, there was no instability as no bony involvement was noted. However, the presence of neurological findings with cord compression on MRI would indicate surgical treatment.

Before the advent of drug therapy, systemic blastomycosis had mortality rates as high as $78 \% .{ }^{12}$ However, this was vastly improved with the use of amphotericin $\mathrm{B}$, which was previously considered the treatment of choice for all forms of blastomycosis. Presently, newer agents such as ketoconazole and itraconazole are useful alternatives with fewer side effects such as bone marrow suppression and renal function impairment. ${ }^{13}$ Cure rates with these agents for non-CNS blastomycosis have been reported as $79-100 \%$ and $90 \%$ respectively with six-month and at least two-month periods. Current recommendations for disseminated CNS blastomycosis include amphotericin B or fluconazole if that is not tolerated. Fluconazole is thought to have superior CNS penetration over ketoconazole and itraconazole. $^{14}$

No clear recommendations were available in the literature for the present case as it is so unusual. Due to the potentially devastating consequences of an intramedullary lesion in an otherwise healthy pediatric patient, and previous treatment failure with itraconazole, this patient was given a five week course of amphotericin B. Relapse rates of most patients treated with amphotericin B are less than 5\%. ${ }^{14}$ The combination of surgical intervention and medical therapy proved effective in this case.

\section{REFERENCES}

1. Crampton TL, Light RB, Berg GM, et al. Epidemiology and clinical spectrum of blastomycosis diagnosed at Manitoba hospitals. Clin Infect Dis 2002; 34: 1310-1316.

2. Bradsher RW. Blastomycosis. Clin Infect Dis 1992; 14[Suppl 1]: 82-90.

3. Witorch P, Utz JP. North American blastomycosis: a study of 40 patients. Medicine 1968; 47: 169-200.

4. Saccente M, Abernathy RS, Pappas PG, Shah HR, Bradsher RW. Vertebral blastomycosis with paravertebral abscess: report of eight cases and review of the literature. Clin Infect Dis1998; 26: 413-418.

5. Hadjipavlou AG, Mader JT, Nauta HJW, et al. Blastomycosis of the 
lumbar spine: case report and review of the literature, with emphasis on diagnostic laboratory tools and management. Eur Spine J 1998; 7: 416-421.

6. Colombo N, Berry I, Norman D. Infections of the spine. In: Manelfe C, (Ed.) Imaging of the Spine and Spinal Cord. New York: Raven Press, 1992: 489-512.

7. Thomas GM. Blastomycosis. In: Feigin RD, Cherry JD, (Eds.) Textbook of Pediatric Infectious Diseases. Philadelphia: W.B. Saunders Co., 1992: 1898-1906.

8. Hardjasudarma M, Willis B, Block-Payne C, Edwards R. Pediatric spinal blastomycosis. Neurosurgery 1995; 37: 534-536.

9. Lagging LM, Breland CM, Kennedy DL, et al. Delayed treatment of pulmonary blastomycosis causing vertebral osteomyelitis, paraspinal abscess and spinal cord compression. Scand J Infect Dis 1994; 26: 111-115.
10. Tuttle JG, Lichtwardt HE, Altshuler CH. Systemic North American blastomycosis: report of a case with small forms of blastomycetes. Am J Clin Pathol 1953; 23: 890-897.

11. Gonyea EF. The spectrum of primary blastomycotic meningitis: a review of central nervous system blastomycosis. Ann Neurol 1978; 3: 26-39.

12. Martin DS, Smith DT. Blastomycosis. I. A review of the literature. Am Rev Tuberc 1939;39: 275-304.

13. Hardman JG, Limbird LE. Goodman and Gilman's The Pharmacological Basis of Therapeutics, ed 10. New York: McGraw-Hill Professional Publishing, 2001.

14. Chapman SW. Blastomycosis dermatitides. In: Mandell GL, Bennett JE, Dolin R, (Eds.) Principles and Practice of Infectious Diseases, 5 ed. New York: Churchill Livingston, 2000: 27332746. 